\title{
Inhibition of emotion-related autonomic arousal by skin pressure
}

\author{
Wataru Sato*
}

\begin{abstract}
Background: Negative emotions can cause discomforting autonomic arousal, which can be difficult to inhibit using willpower alone. Although previous physiological studies have reported that skin pressure at certain bilateral locations reflexively inhibits sympathetic nervous system activity, few studies have tested the effect of this inhibition on emotion-related autonomic arousal in humans.

Findings: I recorded skin potential response (SPR) and heart rate (HR) in healthy participants in response to loud noises presented concomitantly with or without skin pressure applied bilaterally to the sides of the chest. Weaker SPR and lower HR were observed in response to the noises accompanied by skin pressure.

Conclusions: These findings indicate that skin pressure can be an easy and effective method to inhibit autonomic arousal related to negative emotions.
\end{abstract}

Keywords: Autonomic nervous system, Heart rate, Negative emotion, Skin potential response, Skin pressure reflex

\section{Background}

Intense negative emotions, such as fear, elicit autonomic arousal, which can include cold sweat and rapid heartbeat. Although emotion-related autonomic arousal has been proposed as an evolutionarily acquired survival advantage (Porges 2009), it can also be a source of discomfort and have negative effects on behavior in modern humans (Williamson et al. 2013).

Inhibiting emotion-related autonomic arousal through willpower is quite difficult. Several mind-body intervention practices have been proposed, including muscle relaxation and deep breathing (for a review, see Kim et al. 2013). However, these practices usually require training for several weeks or more. Furthermore, empirical evidence has not consistently supported the efficacy of such practices on the activity of the autonomic nervous system (Kim et al. 2013). Developing easy and effective methods to inhibit autonomic arousal related to negative emotions would benefit all humans.

\footnotetext{
*Correspondence: sato.wataru.4v@kyoto-u.ac.jp

Department of Neurodevelopmental Psychiatry, Habilitation

and Rehabilitation, Graduate School of Medicine, Kyoto University, 54

Shogoin-Kawaharacho, Sakyo, Kyoto 606-8507, Japan
}

Previous physiological studies have reported that various species, including mice, cats, and humans, have a skin pressure reflex whereby mechanical pressure on certain bilateral epidermal areas reflexively inhibits the activity in the sympathetic nervous system (e.g., Takagi 1952; for a review, see Takagi 1975). The effects of skin pressure were exhibited in various types of autonomic measures, including skin potential response (SPR) and heart rate (HR) (Takagi 1952). The receptors of this reflex were found to lie in the skin organ (Takagi 1949). It was speculated that this reflex may have evolved to serve a basic biological function, such as a mother calming her children by biting their skin (Takagi 1975).

These data led to the hypothesis that the skin pressure reflex could suppress emotion-related autonomic arousal. Consistent with this idea, a previous study has anecdotally reported that cats do not exhibit emotional reactions in response to physical shocks to their tails while they are receiving skin pressure (Takagi 1975). However, few studies investigated the effects of skin pressure on emotion-related autonomic arousal in humans. One study described that SPRs in response to electrical shock appeared to be inhibited in humans as a result of skin pressure (Hayashi 1952). However, the study did not

\section{黛 Springer}

(c) 2015 Sato. This article is distributed under the terms of the Creative Commons Attribution 4.0 International License (http:// creativecommons.org/licenses/by/4.0/), which permits unrestricted use, distribution, and reproduction in any medium, provided you give appropriate credit to the original author(s) and the source, provide a link to the Creative Commons license, and indicate if changes were made. 
perform statistical analysis, and hence the evidence was not strong.

In the present study, I evaluated my hypothesis by recording SPR and $H R$, which reflect emotion-related autonomic arousal (Palomba et al. 2000), in response to loud noises, which are unconditioned stimuli that induce negative emotions (Damasio et al. 1990), in healthy participants presented concomitantly with or without bilateral skin pressure to the sides of the chest.

\section{Methods}

\section{Participants}

Twelve male volunteers (aged 19-29 years) participated in the experiment. All of the participants confirmed that they had normal hearing abilities and did not have any abnormal autonomic conditions such as those caused by the use of psychiatric medication. All participants gave informed consent to participate in this study, which was conducted in accordance with the ethical provisions of the Kyoto University Graduate School of Education and the Declaration of Helsinki.

\section{Equipment}

A Synafit 360 polygraph system (San-ei, Tokyo, Japan) was used to continuously record SPR and HR. SPR was recorded using $\mathrm{Ag} / \mathrm{AgCl}$ electrodes attached to the hypothenar eminence and forearm of the left hand. HR was recorded using a photoplethysmograph positioned on the last phalange of the left second finger with automatic online calculations of beats per minute. Data were filtered through a bandpass of $0.15-15 \mathrm{~Hz}$ and recorded on paper at $2 \mathrm{~mm} / \mathrm{s}$.

Skin pressure was applied using two handmade devices. The devices consisted of springs, which measured force, and 8 -cm-wide square plates (i.e., $64 \mathrm{~cm}^{2}$ in area), which were flexible in order to fit the body surface.

Loud noises were created by using sports percussion caps (Evernew, Tokyo, Japan). A handmade remote control device was used to generate the noises. The device was placed $2.0 \mathrm{~m}$ behind participants. The sound level used was approximately $110 \mathrm{~dB}$.

\section{Procedure}

Experiments were conducted individually in an electrically shielded soundproof room. After the electrodes and photoplethysmograph were applied, each participant was seated comfortably in a chair in front of a white wall. Participants were requested to sit without leaning against the back of the chair; this position was selected because the skin of the back was found to be sensitive to the skin pressure reflex while the skin of the buttocks was not (Yamada 1950; see Additional file 1: Figure S1). Participants were given $10 \mathrm{~min}$ to adapt to the experiment room, and were then informed about the skin pressure and stimulus presentation. They were requested to relax and not to make body movements or breathe deeply. For practice, they received the skin pressure three times, for approximately $10 \mathrm{~s}$ each time, and were subjected to the noise once.

Skin pressure was applied from behind the participants by the experimenter using the pressure device. Pressure was applied bilaterally to the sides of the chest, centered at the points where the horizontal line that connects the nipples crosses the vertical lines that run downward from the armpits, which were found to be the most sensitive body parts for this skin pressure reflex (Yamada 1950). The amount of pressure was set at $10 \mathrm{~kg} / 64 \mathrm{~cm}^{2}$, because previous studies have reported that the minimum intensity required to elicit this reflex is $3-6 \mathrm{~kg} / 20 \mathrm{~cm}^{2}$ (Takagi 1954), that the reflex is more evident with more pressure and more surface area (Kawai 1954), and that the reflex disappears when the pressure causes subjective discomfort (Takagi 1975).

Four trials of noise presentation were conducted, consisting of two trials of each skin pressure conditions (pressure versus no pressure). Note that physiological responses to loud noises have been reported in as few as a single trial (e.g., Damasio et al. 1990; Lader and Wing 1964). In each trial, the noise was presented $10 \mathrm{~s}$ after an oral warning. In the skin pressure condition, pressure was applied simultaneously with the warning and continued for $25 \mathrm{~s}$. Under the no-pressure condition, no pressure was applied. Intertrial intervals were $3 \mathrm{~min}$. The two skin pressure conditions were presented one after the other, and the order was counterbalanced across participants.

\section{Data analysis}

The data were analyzed using SPSS 10.0J (SPSS Japan). For SPR, peak-to-peak amplitude was calculated by subtracting the maximum negative deflection from the maximum positive deflection (cf. Hori et al. 1970; Knezevic and Bajada 1985) for $15 \mathrm{~s}$ after noise onset. HR change was calculated by subtracting mean HR during the $15 \mathrm{~s}$ after noise onset from those during the $10 \mathrm{~s}$ before noise onset. HR data from two participants were excluded from analysis because of equipment failure. SPR and HR data were averaged for each condition for each participant, and then analyzed by paired $t$ tests. Preliminary analyses revealed that the HR did not differ significantly across the skin pressure vs. no-pressure conditions during the $10 \mathrm{~s}$ prior to noise onset $[M \pm S E=70.0 \pm 2.2$ vs. $69.5 \pm 2.4$ beats per minute; $t(9)=0.62, p>.1$, thereby supporting the validity of pre- vs. post-stimulus period subtraction; SPR peak-to-peak amplitude was significantly lower during the skin pressure condition compared 
to the no-pressure condition $[M \pm S E=1.6 \pm 0.5$ vs. $3.5 \pm 0.6 \mathrm{mV} ; t(11)=2.54, p<.05$; also discussed below].

\section{Results}

After exposure to the loud noise, SPR peak-to-peak amplitude (Figure 1, left) was significantly lower under the skin pressure condition than the no-pressure condition $[t(11)=2.69, p<.05]$. HR change (Figure 1, right) was also significantly reduced under the skin pressure condition than the no-pressure condition $[t(9)=3.54$, $p<.01]$.

\section{Discussion}

Both SPR and HR measures were reduced in response to loud noises under the bilateral skin pressure condition compared with the no-pressure. These results are consistent with previous evidence that bilateral skin pressure reflexively inhibits widespread sympathetic nervous activity (Takagi 1975). The results are also consistent with the finding that skin pressure modulates emotion-related autonomic arousal (Hayashi 1952). However, this previous investigation was descriptive. To my knowledge, this is the first statistically supported evidence that emotionrelated autonomic arousal can be inhibited by bilateral skin pressure.

These results may have practical applications because emotion-related autonomic arousal can negatively influence human wellbeing, and can be reduced using skin pressure. Consistent with this idea, several researchers found similar phenomena through their experiences and utilized them to improve emotional states. For example, Grandin observed that cattle remained calm when receiving bilateral pressure to large areas while in a cattle chute, and later applied this technique to herself; she found that the application of skin pressure helped her to relax, and developed a device for humans (Grandin and

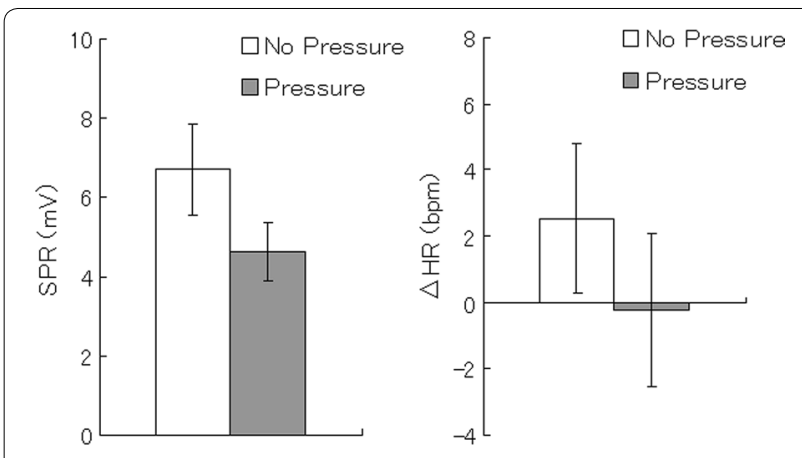

Figure 1 Mean (with SE) skin potential responses (SPRs) and heart rate changes $(\Delta H R)$ in beats per minute (bpm) in response to loud noises without and with skin pressure.
Scariano 1986). She and her colleagues reported that the device reduced tension in normal adults (Grandin 1992) and anxious children with developmental disorders (Edelson et al. 1999). The current results provide physiological evidence to support the efficacy of such applications, and suggest that bilateral skin pressure may be an easy and effective method to inhibit emotion-related autonomic arousal.

Preliminary analysis showed that the SPR peak-to-peak amplitude was lower during the skin pressure condition compared to the no-pressure condition prior to noise onset. It should be noted that such a difference, occurring during the baseline period, would not change the interpretation of the inhibitory effect of skin pressure on emotional arousal, because the direction of the effect was opposite to the law of initial value. In which high pre-stimulus values generally induce small post-stimulus changes (Wilder 1962). It is possible that the warnings provided regarding the loud noises elicited anticipatory emotional responses (cf. Epstein and Clarke 1970), but the application of skin pressure inhibited these responses.

This study had several limitations that should be acknowledged. First, only a small sample of young males was recruited. Therefore, additional investigations using larger samples, and including participants of different genders and ages, are required to establish the effect of skin pressure on emotion-related autonomic arousal. Second, the comparison was conducted using only conditions of skin pressure and no-pressure, as in a previous study (Hayashi 1952). This design could be affected by confounding factors related to body contact (but not to the skin pressure reflex) such as attentional shift. Because a previous study reported that the effect of skin pressure differed according to body area in terms of restingstate autonomic activity (Yamada 1950), future studies should compare the effects of skin-pressure on responsive vs. non-responsive areas to clarify this issue. Finally, only loud noises were used to induce negative emotions, such that the generalizability of the skin-pressure effect to other types of emotional stimuli remains unproven. Future studies employing other types of emotional stimuli, such as photographs and scenarios depicting emotional events, could be used to confirm the autonomic-inhibitory effect of skin pressure related to negative emotions.

\section{Conclusions}

In summary, SPR and HR were reduced in response to the loud noises under conditions of bilateral skin pressure relative to no-pressure. These results suggest that skin pressure can be an easy and effective method to inhibit autonomic arousal related to negative emotions. 


\section{Additional file}

Additional file 1: Figure S1. The response-distribution of the skin pressure reflex throughout the whole body (Yamada 1950). The figure is used with permission from the publisher. +++ the most responsive; ++ highly responsive; + responsive; \pm sometimes responsive; - not responsive.

\section{Acknowledgements}

The author thanks Dr. Matsuura, Mr. Ishigame, Dr. Nishio, Dr. Hirose, and Dr. Sakano for their technical support.

\section{Compliance with ethical guidelines}

\section{Competing interests}

The author declares that he has no competing interests.

Received: 20 April 2015 Accepted: 15 June 2015

Published online: 26 June 2015

\section{References}

Damasio AR, Tranel D, Damasio H (1990) Individuals with sociopathic behavior caused by frontal damage fail to respond autonomically to social stimuli. Behav Brain Res 41:81-94

Edelson SM, Edelson MG, Kerr DCR, Grandin T (1999) Behavioral and physiological effects of deep pressure on children with autism: a pilot study evaluating the efficacy of Grandin's Hug Machine. Am J Occup Ther 53:145-152

Epstein S, Clarke S (1970) Heart rate and skin conductance during experimentally induced anxiety: effects of anticipated intensity of noxious stimulation and experience. J Exp Psychol 84:105-112
Grandin T (1992) Calming effects of deep touch pressure in patients with autistic disorder, college students, and animals. J Child Adolesc Psychopharmacol 2:63-72

Grandin T, Scariano MM (1986) Emergence: labeled autistic. Arena Press, Novato

Hayashi S (1952) Atsu-hansha nikansuru kenkyu. Nigata Igakukai Zasshi 66:775-785

Hori T, Miyasita A, Niimi Y (1970) Skin potential activities and their regional differences during normal sleep in humans. Jpn J Physiol 20:657-671

Kawai H (1954) Hito no bikoukaiondo nitaisuru hifuappaku no eikyou. Nihon Seirigaku Zasshi 16:647-655

Kim SH, Schneider SM, Kravitz L, Mermier C, Burge MR (2013) Mind-body practices for posttraumatic stress disorder. J Invest Med 61:827-834

Knezevic W, Bajada S (1985) Peripheral autonomic surface potential. A quantitative technique for recording sympathetic conduction in man. J Neurol Sci 67:239-251

Lader MH, Wing $L$ (1964) Habituation of the psycho-galvanic reflex in patients with anxiety states and in normal subjects. J Neurol Neurosurg Psychiatry 27:210-218

Palomba D, Sarlo M, Angrilli A, Mini A, Stegagno L (2000) Cardiac responses associated with affective processing of unpleasant film stimuli. Int J Psychophysiol 36:45-57

Porges SW (2009) The polyvagal theory: new insights into adaptive reactions of the autonomic nervous system. Cleve Clin J Med 76:86-90

Takagi K (1949) Hansokuhakkan no doki nitsuite. Nihon Seirigaku Zasshi 11:137-141

Takagi K (1952) Seitai niokeru kohun to yokusei. No to Shinkei 4:201-207

Takagi K (1954) Hifuatsu, jiritsusinkeihansya. Saishin Igaku 9:639-654

Takagi K (1975) Seitai no chosetsukinou. Chuokoronsha, Tokyo

Wilder J (1962) Basimetric approach (law of initial value) to biological rhythms. Ann N Y Acad Sci 98:1211-1220

Williamson JB, Heilman KM, Porges EC, Lamb DG, Porges SW (2013) A possible mechanism for PTSD symptoms in patients with traumatic brain injury: central autonomic network disruption. Front Neuroeng 6:13

Yamada T (1950) Hakkanseihansya nitsuite. Nigata Igakukai Zasshi 64:707-711

\section{Submit your manuscript to a SpringerOpen ${ }^{\odot}$ journal and benefit from:}

- Convenient online submission

- Rigorous peer review

- Immediate publication on acceptance

- Open access: articles freely available online

- High visibility within the field

- Retaining the copyright to your article

Submit your next manuscript at $>$ springeropen.com 